\title{
Dental Implant Expectations among Partially and Completely Edentulous Patients
}

\author{
${ }^{1}$ Maha A Mekkawy, ${ }^{2}$ Huda A Almutairi
}

\section{ABSTRACT}

Purpose: To assess edentulous patient awareness, expectations, and source of information about dental implants (DIs).

Materials and methods: Edentulous patients' knowledge and awareness in using DIs, as an option in replacing missing teeth, either in implant-supported fixed prosthesis or implantsupported overdenture, were evaluated through a standardized self-explanatory questionnaire distributed in three places: King Saud Hospital, AL Harkan Private Dental Clinics (in Unaizah), and College of Dentistry, Qassim University. The questionnaires were either handed to the patients during their regular dental visits or asked by the dentist. A total of 178 subjects were included in this survey.

Results: About $93.3 \%$ of participants were aware of DIs, with statistically significant difference between the study groups $(p=$ 0.012 ). The participants' friends and relatives were the main source of information (49.40\%), followed by dentists (33.70\%). Approximately $41.60 \%$ were moderately informed about DIs. Over one-third of patients expected an implant to require more care than natural teeth (39.80\%). About $65.3,73.6$, and $80 \%$ of single missing, partially, and completely edentulous patients respectively, preferred to have their teeth replaced with DIs. Improvement in function was the predominant reason for completely edentulous patients (57.9\%) to consider DIs, while 37.6 and $41.4 \%$ of single missing and partially edentulous patients were considered DIs to avoid adjacent teeth damaging. Fear of surgical risks was the major factor in preventing patients from choosing DIs (13.5\%), followed by high cost (9.6\%) and unknown side effects (6.2\%).

Conclusion: There was a high awareness about DIs among removable denture patients; however, this awareness was associated with a low level of accurate information.

Recommendations: There is a need to provide more accurate information about DIs to the patients by the dentists.

Keywords: Dental implants, Edentulous patients, Information sources, Patient's awareness, Prosthodontics.

How to cite this article: Mekkawy MA, Almutairi HA. Dental Implant Expectations among Partially and Completely Edentulous Patients. J Contemp Dent 2017;7(1):28-34.

\footnotetext{
${ }^{1}$ Assistant Professor, ${ }^{2}$ Intern

${ }^{1}$ Department of Removable Prosthodontics, College of Dentistry Qassim University, Buraidah, Qassim, Kingdom of Saudi Arabia

${ }^{2}$ Department of Removable Prosthodontics, College of Dentistry Qassim University, Unaizah, Qassim, Kingdom of Saudi Arabia

Corresponding Author: Maha A Mekkawy, Assistant Professor Department of Removable Prosthodontics, College of Dentistry Qassim University, Buraidah, Qassim, Kingdom of Saudi Arabia Phone: +966552877029, e-mail: mahaahmed2024@gmail.com
}

\author{
Source of support: Nil
}

Conflict of interest: None

\section{INTRODUCTION}

Today, modern implant dentistry appeals to a wider population, but the knowledge and expectations of patients are important for the success of implants. ${ }^{1}$ Dental implants (DIs) are widely accepted for prosthetic treatment of completely or partially edentulous patients. ${ }^{2-5}$ Implant-supported prostheses have shown advantages, such as increased masticatory efficiency, maintenance of bone, improved function, phonetics, and esthetics. ${ }^{6,7}$ However, information about DI patients' expectations is limited. ${ }^{8}$ Most published studies have reported on satisfaction with treatment outcomes. ${ }^{9-12}$ Awareness about implant treatment procedures among a selected group of patients varies; it was found to be $29 \%$ in Finland, 64\% in Australia, 72\% in Austria, 23.24\% of urban Indian populations, $77 \%$ in the United States, $66.4 \%$ in Saudi Arabia, and 9.7\% among health workers in Nigeria. ${ }^{13-17}$

In Rustemeyer and Bremerich ${ }^{1}$ study, which aimed to evaluate the level of patient knowledge regarding DI, $58 \%$ of 315 patients questioned thought that implants require the same care as natural teeth, $80 \%$ held the function of an implant-supported overdenture as very important, and $54 \%$ attached great importance to the esthetics. The expectations that patients have for an implant-supported set are high in contrast to their willingness to make additional payments.

Baracat et al ${ }^{16}$ compared patients' expectations before implant treatment with their satisfaction regarding function and esthetics after DI therapy. Fifty volunteers answered a questionnaire about influencing variables and underwent an initial examination followed by implant therapy. Their expectations regarding esthetics and function were verified on a visual analog scale (VAS) before treatment. The VAS was also used for posttreatment completion rating. They found that patients' posttreatment completion ratings significantly exceeded their initial expectations.

In another study, Al-Johany et $\mathrm{al}^{17}$ assessed the level, sources, and need for information about DIs among a selected sample of dental patients in Riyadh, Saudi 
Arabia, through a standardized self-explanatory questionnaire. The results of this survey showed that $66.4 \%$ of 379 subjects knew about DIs mainly from their friends and relatives, followed by the dentists. The high cost was the major factor in preventing patients from choosing implants in $86.5 \%$ of the cases, while the long treatment time and fear of surgery were the factors in 71 and $68.6 \%$ of the subjects respectively.

Müller et $\mathrm{al}^{18}$ evaluated the potential barriers for accepting an implant treatment in elderly patients. The sample comprised 92 persons, 61 women, and 31 men. The results showed that 27 participants had never heard of DIs, and another 13 participants could not describe them. The strongest apprehensions against implants were cost, lack of perceived necessity, and old age. However, providing further information and promoting oral health, in general, might increase the acceptance of DIs in the elderly population.

Al-Dwairi et $\mathrm{al}^{19}$ assessed removable denture patient awareness, expectations, and sources of information about DIs. The study showed that $96 \%$ of participants (300 patients) [150 removable partial denture (RPD) wearers and 150 complete denture (CD) wearers] were aware of DIs, with no difference between CD and RPD wearers. The participants' friends and relatives were the main sources of information, followed by dentists. Improvement in function was the predominant reason (55.7\%) for patients considering DIs. Fear of unknown side effects was the major factor in preventing patients from choosing DIs (11.7\%), followed by high cost (9.7\%) and surgical risk (8.7\%). Approximately $89 \%$ had no information or were poorly informed about DIs. Over two-thirds of patients did not know about the care of DIs, causes of DI failure, or DI duration of service. Only $24.7 \%$ knew that DIs would be anchored to the jawbone; however, 27.3 and $56.7 \%$ of CD wearers and RPD wearers respectively, preferred to have their teeth replaced with DIs.

The aim of this study was to assess the patient expectation, and sources of information about DIs among edentulous patients in addition to evaluate the level of patient knowledge about DIs among a selected sample of dental patients.

\section{MATERIALS AND METHODS}

A standardized questionnaire with 15 multiple-choice questions was developed in order to generate an accessible patient profile including personal data, education, and state of the oral cavity (single missing, partially or completely edentulous). The questionnaire included 12 special questions about implants to gauge the patients' knowledge about the DI, oral hygiene considerations, durability, and the esthetic and functional importance of an implant. Furthermore, the questionnaire included patient preference to replace the missing teeth either with fixed or removable prosthesis or implant and the reasons for whether they prefer DI or not. The other three questions were specified for the completely edentulous patients to evaluate patients' expectations regarding implant-supported overdenture and implant-supported fixed bridge and the reasons in case they prefer implant-supported overdenture. This information was fundamental to evaluate the state of patient knowledge and expectations before detailed consultations and clarifying conversations were held.

Two hundred questionnaires were distributed to female and male patients attending Dental Clinics, Qassim University, King Saud Hospital, and Al Harkan Private Dental Clinics after taking acceptance from the ethics committee in the college (EN/1/20I5) over a period of 4 months. Hard copy papers and electronic methods were used to conduct the questionnaires among the patients. A patient was excluded from the study under any of the following circumstances: the answers to the 12 special questions were incomplete, if there are contrast answers, or if the age was below the determined range; $89 \%$ of the respondents were included in the study; these 178 patients were 126 women and 52 men (mean age 20-65 years), consisting of 19 completely edentulous patients, 58 partially edentulous patients, and 101 patients with single or multiple separated missing teeth.

The collected data were analyzed by using Statistical Package for Social Sciences (SPSS Inc., Chicago, IL) software, and statistical analyses were performed with Chi-square test to compare the descriptive data.

\section{RESULTS}

\section{Demographic Data}

Approximately $68 \%$ of the participants $(n=121)$ were between 20 and 39 years, $28.1 \%(n=50)$ were between 40 and 59 years, $3.9 \%(n=7)$ were 60 years or more; $70.8 \%$ were female compared with $29.2 \%$ male (Table 1 ). The majority $(69.3 \%)$ of single missing cases, $67.2 \%$ of partially edentulous cases, and $89.5 \%$ of completely edentulous cases were female. According to oral status, significantly more single missing cases were between 20 and 39 years compared with partially edentulous cases where most were between 40 and 59 years and completely edentulous cases, where most were 60 years or more. According to education, the majority $(78.2 \%)$ of single missing and partially edentulous cases were university educated, while $36.8 \%$ of completely edentulous cases were primary school educated.

\section{Patient's Information}

Regarding hearing about implants, there was a statistically significant difference between the study groups 
Table 1: Distribution of the study population by oral status according to age, gender, and education

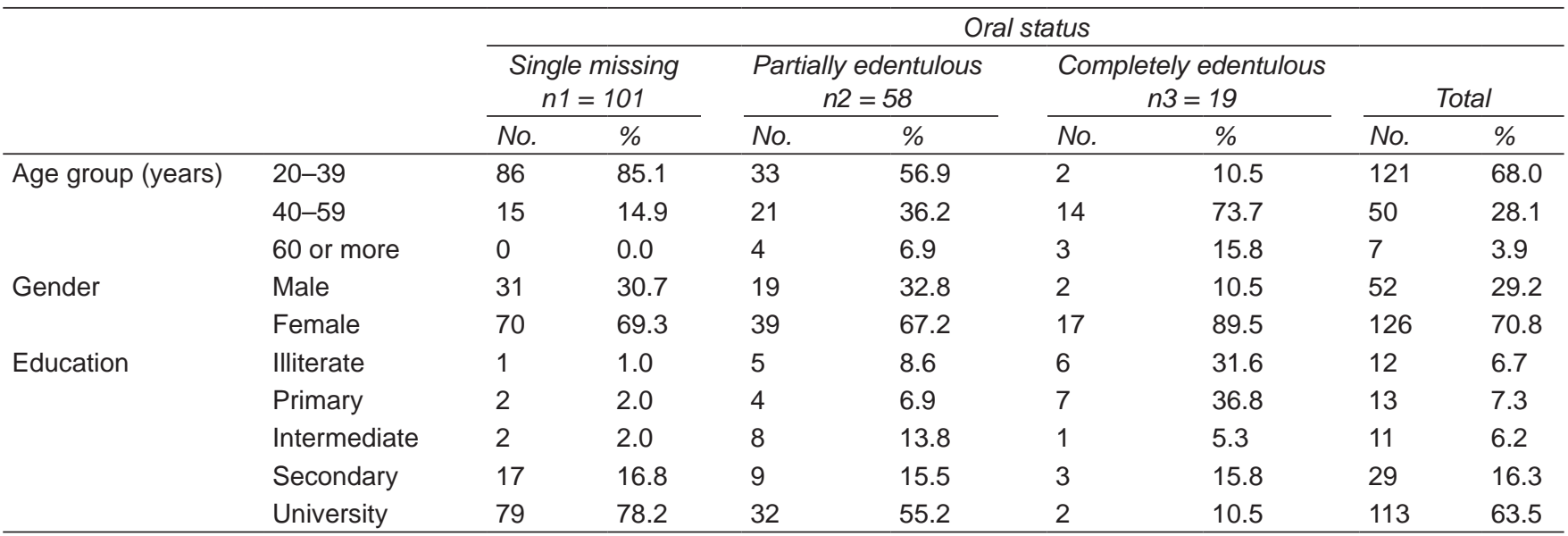

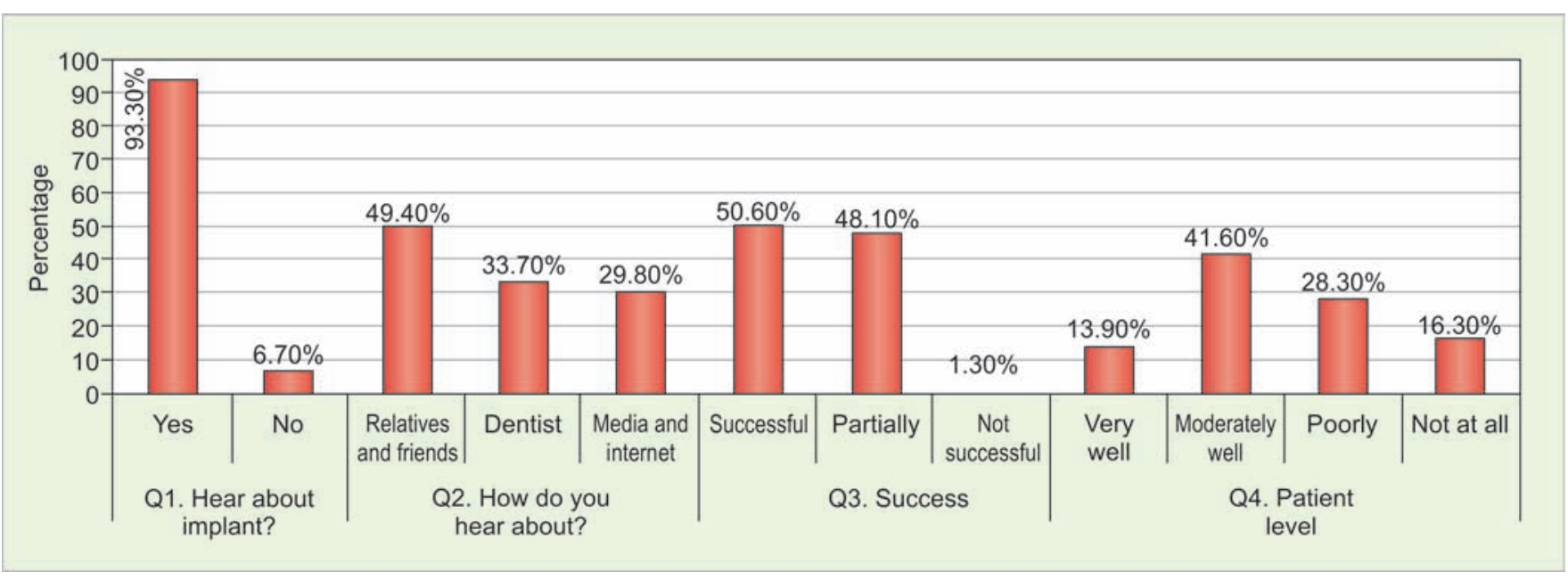

Graph 1: Comparison between the study groups regarding their information

( $p=0.012 ;$ Graph 1). The main source of information for $49.5 \%$ of single missing cases was relatives and friends, followed by media and internet and then dentists. Also, relatives and friends were the main sources of information for the majority of partially edentulous cases (46.6\%) and of completely edentulous cases (49.4\%), but followed by dentists then media and internet, with significance difference between study groups for media and internet as source of DI information $(p<0.05)$. With regard to the success of DI treatment, $50.6 \%$ of the participants who heard about DI experiences from the different sources reported success with DI experiences, while $48.1 \%$ reported partially success experiences, and $1.3 \%$ reported unsuccessful experiences. For the patient level of information, there was a significance difference between the study groups ( $\mathrm{p}=0.016$ ) as $18.9 \%$ of the partially edentulous cases revealed a very good level of information. While $45.9 \%$ showed a moderately good level of information, $33.3 \%$ of the completely edentulous cases had a poor level of information, while $40 \%$ had no information about DIs.

\section{Level of Information}

Only $69.9 \%$ believed that patient systemic health was important when considering implant therapy, and 30.1\% were not aware of such importance (Graph 2). Concerning oral hygiene in the care of implants, $39.8 \%$ of the patients questioned expected an implant to require more care than natural teeth; $19.9 \%$ estimated the care to be similar. Only $12.0 \%$ of the patients expected that less care would be needed, while $28.3 \%$ had no idea, with no significant differences between the study groups. Most participants (52.4\%) had no idea about how long an implant would last, and only $22.3 \%$ thought that implant would last between 10 and 20 years, followed by 19.3\% who thought that it would last more than 20 years and $6 \%$ who thought it would last less than 10 years; $71.7 \%$ of the participants found the esthetic appearance of the implant to be a very important consideration, while $1.2 \%$ found it as not very important. Significant differences between single missing cases, partially and completely edentulous patients existed in their evaluation of the importance of the chewing function of an implant set; $77.1 \%$ of the 


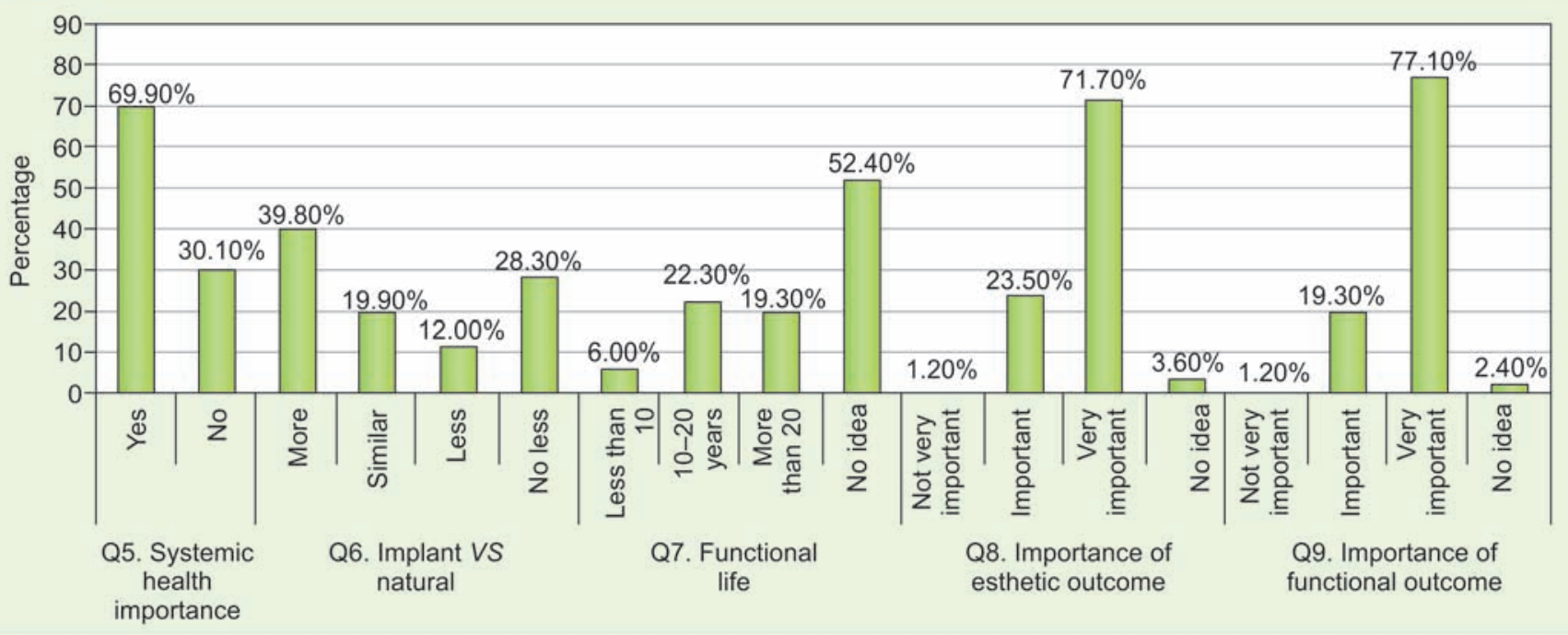

Graph 2: Comparison between the study groups regarding level of information

participants judged this as very important, but only $1.2 \%$ judged as not very important $(\mathrm{p}<0.05)$.

\section{Level of Acceptance}

About $1,1.9$, and $13.3 \%$ of single missing, partial, and completely edentulous cases favored removable prosthetic options respectively. By contrast, 30.6, 24.5, and 6.7\% of three groups preferred to have fixed prostheses. Around $64,73.6$, and $80 \%$ favored their teeth to be replaced with DIs. Only $3.1 \%$ of the single missing cases reported no replacement (Graph 3). Approximately 69.3\% preferred to replace missing teeth by implants if such treatment was possible: $30.7,27.6$, and $31.6 \%$ of three groups for esthetic, $29.7,34.5$, and $57.9 \%$ for functional reasons. In addition, $37.6,41.4$, and $15.8 \%$ preferred having implants to avoid damaging adjacent teeth. Fear of surgical risks was the major reason preventing patients from choosing implants
(13.5\%), followed by high costs $(9.6 \%)$, unknown scare $(7.9 \%)$, and long treatment times (6.2\%).

\section{Patient's Expectation for Completely Edentulous Patients Only}

Graph 4 reflects that $20 \%$ of the completely edentulous participants preferred implant-supported overdentures over implant-supported fixed bridges for its function (20\%) followed by esthetics (6.67\%). The majority do not prefer it because they consider it a removable prosthodontics $(53.33 \%)$ or they are scared of postinsertion complaints $(26.67 \%)$, so they prefer implant-supported fixed bridges $(66.67 \%)$.

\section{DISCUSSION}

This study was conducted among the patients attending the dental clinics regarding knowledge, awareness, and

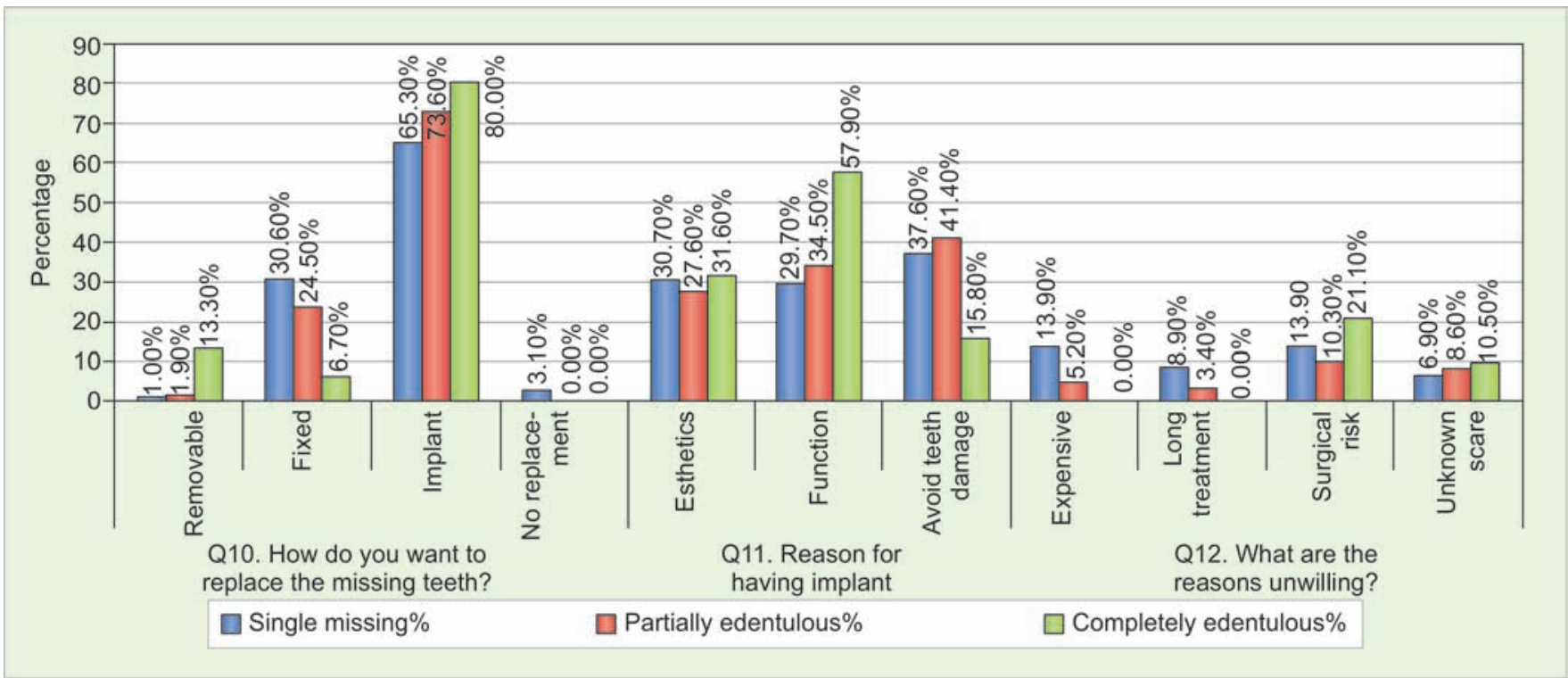

Graph 3: Comparison between the study groups regarding their level of acceptance 


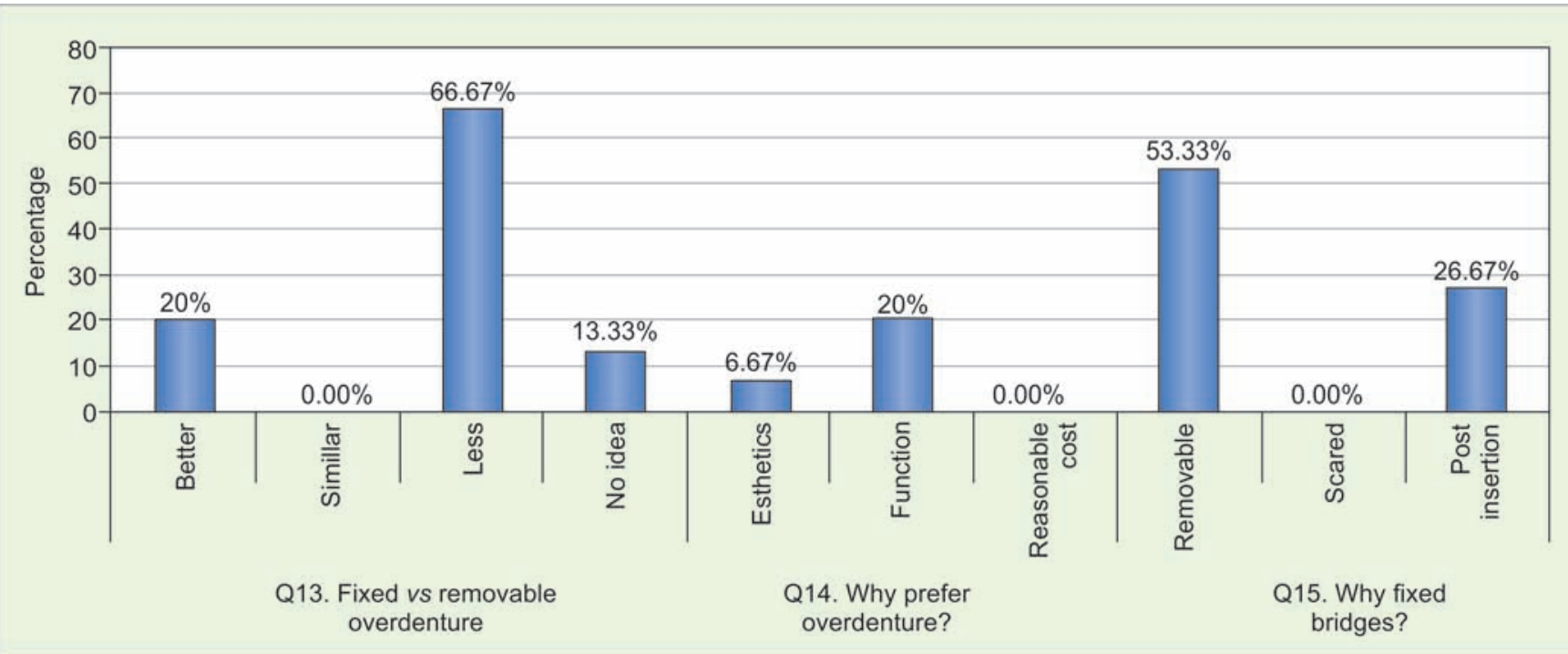

Graph 4: Patients' expectation for completely edentulous patients only

acceptance about DIs as a treatment modality for replacing missing teeth.

Similar to Al-Dwairi et al $_{1}^{19}$ the present study used a sample of patients with a wide age range enabling the authors to assess awareness of DIs in different age groups.

Concerning hearing about DIs, in this study, the majority of patients were aware of DI as an option for missing teeth replacement, which almost coincides with the results of Al-Johany et $\mathrm{al}^{17}$ Müller et $\mathrm{al}^{18}$ and AlDwairi et al ${ }^{19}(66.4 \%)$.

Regarding the sources of information about DIs, this survey showed that the main source of information was relatives and friends, followed by dentists and lastly the media and internet. Only $29.8 \%$ of the interviewees claimed that their primary source of information about DIs had been the internet, TV/radio, or newspapers/ magazines. The less role of internet information partially might be due to the lack of internet access and lower educational status.

Our results were in agreement with those of Al-Johany et $\mathrm{al}_{1}{ }^{17}$ who found that relatives and friends were the main sources of information about DIs for $31.5 \%$ of the questioned subjects (379 patients), followed by dentists (28.3\%). Also, studies by Müller et $\mathrm{al}^{18}$ and Al-Dwairi et a $\mathrm{l}^{19}$ showed similar results. Rustemeyer and Bremerich, ${ }^{1}$ found the most common source of information $(41 \%$ of patients) on the subject of implants was family dentist. Laymen, friends, or the media were seldom relatively the first sources. Although $25 \%$ of the patients found information through several sources, including the internet, use of the internet as a sole source of information was low.

In the present study, the subjective level of information about DIs was moderately well for $41.6 \%$ of the participants, and there was a significant difference between the study groups at $(p=0.016)$. This is different from the results reported by Al-Dwairi et $\mathrm{al}^{19}$ in which only $0.3 \%$ of the participants felt very well informed about DIs, while $64 \%$ of the participants claimed that they were not informed about DIs in any way, while only $10 \%$ were moderately informed.

Regarding the importance of systemic health, $69.9 \%$ of the participants believed that patient systemic health was important when considering implant therapy and $30.1 \%$ were not aware of such importance. This might be due to the majority of cases being university educated. The result coincides with the study of Al-Dwairi et a ${ }^{19}$, in which only $66 \%$ agreed with the importance of systemic health, and $32.3 \%$ did not agree with this importance.

Concerning oral hygiene in the care of the implants, the majority $(39.8 \%)$ of the patients questioned expected an implant to require more care than natural teeth, which might reflect their expectations toward DIs as foreign bodies and necessitate more care, while $19.90 \%$ expected similar care as natural teeth, $12 \%$ expected less care, and $20.30 \%$ had no idea. This result is different from the results of Rustemeyer and Bremerich ${ }^{1}$ and Al-Dwairi et $\mathrm{al}_{1}{ }^{19}$ while it coincides with the results of Al-Johany et al. ${ }^{17}$

According to DI lifespan, in this study most participants (52.4\%) had no idea about how long an implant would last; this might be due to the low level of the accurate information. Results comparable to findings in this study were reported by Müller et $\mathrm{a}^{18}$ and Al-Dwairi et al. ${ }^{19}$ While in Rustemeyer and Bremerich ${ }^{1}$ study, the majority $(66 \%)$ of the patients expected them to last between 11 and 20 years and this is contrary to the result of the present study.

For patients' missing teeth replacement preferences, there is a significance difference between the study groups. The highest percentage was for the DIs among single, partially, and completely edentulous cases (65.30, 
73.60, and $80 \%$ respectively), followed by fixed bridges for single missing $(30.60 \%)$ and partially edentulous cases $(24.50 \%)$, then removable prosthesis for completely edentulous cases $(13.30 \%)$, which confirms the fact that most patients do not prefer removable prosthesis in replacing their missing teeth regardless of the clinical situation they have. Most of the patients felt that the implants and fixed prosthesis give a better feeling in the mouth and appear more natural. Similarly, in the study of Al-Johany et al, ${ }^{17}$ the majority of the sample $(61.5 \%)$ believed that DIs are the best treatment choice for replacing missing teeth, while $35.2 \%$ said fixed partial dentures and only 3.3\% said removable dentures. In the study by Al-Dwairi et al, 19 approximately $75 \%$ of the participants preferred to replace missing teeth by implants if such treatment was possible.

In the present study, completely edentulous cases prefer DIs for its function, while single and partially edentulous cases prefer it to avoid adjacent teeth damaging. However, fear of surgical risks was the major reason preventing patients from choosing implants $(13.5 \%)$, followed by high costs $(9.6 \%)$, unknown scare $(7.9 \%)$, and long treatment times $(6.2 \%)$. Some patients think that the implant is a major surgical procedure because of the use of the word surgery. This may explain the high fear rate. Results comparable to findings in this study with different in the order reported that the fear of unknown side effects was the strongest argument against implant therapy $(11.7 \%)$ in Al-Dwairi et al ${ }^{19}$ study, followed by high costs $(9.7 \%)$, surgical risks $(8.7 \%)$, postinsertion complaints $(4 \%)$, complicated treatments $(1.7 \%)$, and long treatment times (1\%). By contrast, Rustemeyer and Bremerich ${ }^{1}$ and Zimmer et $\mathrm{al}^{20}$ reported that the cost of an implant-supported overdenture is a major argument against the implant. Al-Johany et al ${ }^{17}$ also demonstrated that high cost was the major factor preventing the questioned subjects from choosing DIs. Müller et al ${ }^{18}$ also agreed with the previous studies in that the cost was a predominant factor against DI therapy.

Regarding implant-supported overdenture, some of the completely edentulous cases prefer the implant-supported overdenture for its function $(20 \%)$, while the majority of them do not prefer it because they consider it a removable prosthodontics so they prefer the implant-supported fixed bridges $(53.33 \%)$, while in Rustemeyer and Bremerich ${ }^{1}$ study, 54 and $79 \%$ participants respectively, found the esthetical and the functionality of the implant-supported overdenture to be the most important consideration.

\section{CONCLUSION}

- The majority of the questioned participants were aware of DIs as an option in replacing missing teeth, and there was a statistically significant difference between the study groups ( $\mathrm{p}=0.012)$.
- Relatives and friends were the main sources of information regarding DIs among the population; however, this awareness was associated with a low level of accurate information about implants.

- The functional and esthetic outcomes were very important for all study groups.

- Concerning oral hygiene in the care of implants, $39.8 \%$ of the patients expected an implant to require more care than natural teeth.

- The majority of completely edentulous cases do not prefer implant overdenture because they consider it a removable prosthodontics so they prefer the implantsupported fixed bridges.

\section{RECOMMENDATIONS}

- The need to provide more accurate information about DIs to the patients by the dentists.

- Do further researches to assess the patients' awareness in the coming years and include more completely edentulous cases in the sample.

\section{ACKNOWLEDGMENT}

Authors would like to especially thank Dr Ramy Elmoazen, lecturer of Community Dentistry and Epidemiology, because of his statistical analysis and King Saud Hospital and Al Harkan private clinics for their help in questionnaire distribution.

\section{REFERENCES}

1. Rustemeyer J, Bremerich A. Patients' knowledge and expectations regarding dental implants: assessment by questionnaire. Int J Oral Maxillofac Surg 2007 Sep;36(9):814-817.

2. Berge TI. Public awareness, information sources and evaluation of oral implant treatment in Norway. Clin Oral Implants Res 2000 Oct;11(5):401-408.

3. Naert I, Koutsikakis G, Duyck J, Quirynen M, Jacobs R, van Steenberghe D. Biologic outcome of implant-supported restorations in the treatment of partial edentulism. Part I: a longitudinal clinical evaluation. Clin Oral Implants Res 2002 Aug;13(4):381-389.

4. Naert I, Koutsikakis G, Quirynen M, Duyck J, van Steenberghe D, Jacobs R et al: Biologic outcome of implant-supported restorations in the treatment of partial edentulism. Part 2: a longitudinal radiographic study. Clin Oral Implants Res 2002 Aug;13(4):390-395.

5. Suprakash B, Ahammed AY, Thareja A, Kandaswamy R, Nilesh K, Bhondwe Mahajan S. Knowledge and attitude of patients toward dental implants as an option for replacement of missing teeth. J Contemp Dent Pract 2013 Jan;14(1):115-118.

6. Kaurani P, Kaurani M. Awareness of dental implants as a treatment modality amongst people residing in Jaipur (Rajasthan). J Clin Diagn Res 2010 Dec;4(6):3622-3626.

7. Lekholm U, Gröndahl K, Jemt T. Outcome of oral implant treatment in partially edentulous jaws followed 20 years in clinical function. Clin Implant Dent Relat Res 2006 Nov;8(4): 178-186. 
8. Allen PF, McMillan AS, Walshaw D. Patient expectations of oral implant-retained prostheses in a UK dental hospital. Br Dent J 1999 Jan;186:80-84.

9. Blomberg S, Lindquist LW. Psychological reactions to edentulousness and treatment with jawbone-anchored bridges. Acta Psychiatr Scand 1983 Oct; 68(4):251-262.

10. Vermylen K, Collaert B, Lindén U, Björn AL, De Bruyn H. Patient satisfaction and quality of single-tooth restorations. Clin Oral Implants Res 2003 Feb;14(1):119-124.

11. Annibali S, Vestri AR, Pilotto A, La Monaca G, Di Carlo S, Cristalli MP. Patient satisfaction with oral implant rehabilitation: evaluation of responses to a questionnaire. Ann Stomatol (Roma) 2010 Jul;1(3-4):2-8.

12. Babbush CA. Post-treatment quantification of patient experiences with full-arch implant treatment using a modification of the OHIP 14 questionnaire. J Oral Implantol 2012 Jun;38(3):251-260.

13. Tepper G, Haas R, Mailath G, Teller C, Bernhart T, Monov G, Watzek G. Representative marketing oriented study on implants in the Austrian population. II. Implant acceptance, patient-perceived cost and patient satisfaction. Clin Oral Implants Res 2003 Oct;14(5):634-642.

14. Chowdhary R, Mankani N, Chandraker NK. Awareness of dental implants as a treatment choice in urban Indian populations. Int J Oral Maxillofac Implants 2010 Mar-Apr;25(2): 305-308.

15. Mgbeokwere U, Okoye L, Ekwueme O. A survey of the knowledge of dental implants as a choice in treatment of edentulous jaws among health workers in government dental clinics in Enugu. Ann Med Health Sci Res 2011 Jan-Jun;1(1):91-95.

16. Baracat LF, Teixeira AM, Fernandes dos Santos MB, Prisco da Cunha VdeP, Marchini L. Patients' expectations before and evaluation after dental implant therapy. Clin Implant Dent Relat Res 2009 Jun;13(2):141-145.

17. Al-Johany S, Al Zoman HA, Al Juhaini M, Al Refeai M. Dental patients' awareness and knowledge in using dental implants as an option in replacing missing teeth: a survey in Riyadh, Saudi Arabia. Saudi Dent J 2010 Oct;22(4):183-188.

18. Müller F, Salem K, Barbezat C, Herrmann FR, Schimmel M. Knowledge and attitude of elderly persons towards dental implants. Gerodontology 2012 Jun;29(2):e914-ee923.

19. Al-Dwairi ZN, El Masoud BM, Al-Afifi SA, BorzabadiFarahani A, Lynch E. Awareness, attitude, and expectations toward dental implants among removable prostheses wearers. J Prosthodont 2014 Apr;23(3):192-197.

20. Zimmer CM, Zimmer WM, Williams J, Liesener J. Public awareness and acceptance of dental implants. Int J Oral Maxillofac Implants 1992 Summer:7(2):228-232. 